\title{
Correlação clínico-laboratorial de úlceras infecciosas de córnea
}

\author{
Correlation between clinical and laboratory findings of infectiouscorneal ulcer
}

\author{
Adália Dias Dourado Oliveira ${ }^{1}$ \\ Itelo Carneiro da Costa ${ }^{1}$ \\ Adael Sansoni ${ }^{2}$ \\ Myrna Serapião ${ }^{3}$ \\ Maria Emília Xavier Santos Araújo ${ }^{4}$
}

\section{RESUMO}

Objetivo: Avaliar a resposta terapêutica inicial instituída para úlceras de córneas infecciosas correlacionando-a com os achados laboratoriais. Métodos: Foram estudados prospectivamente 24 casos de úlcera de córneas infecciosas atendidos no Setor de Córnea e Patologia Externa do Hospital do Servidor Público Estadual - São Paulo, no período entre julho de 1997 e novembro de 1999. Acompanhou-se a resposta destes pacientes ao tratamento antibiótico inicial (cefalotina $50 \mathrm{mg} / \mathrm{ml}$ e gentamicina $14 \mathrm{mg} / \mathrm{ml}$ ou ciprofloxacina $0,3 \%$ ), verificando-se a necessidade de modificação deste tratamento a partir dos testes microbiológicos pré-tratamento. Resultados: Dezessete culturas (70,83\%) foram positivas e sete $(29,17 \%)$ negativas. Apenas em três amostras analisadas pelo exame direto e coradas pelo método de Gram, observou-se a presença de algum microrganismo, sendo que em duas $(8,33 \%)$ houve correlação com a cultura. Três pacientes $(12,5 \%)$ apresentaram piora clínica e foram submetidos à mudança da medicação inicialmente instituída de acordo com a cultura e antibiograma. Todos os pacientes $(100 \%)$ cursaram com a cura do processo infeccioso. Conclusão: Pela análise dos resultados, observa-se que o tratamento tópico com antibióticos de amplo espectro ou associação de colírios com antibióticos fortificados foi, na maioria dos casos, eficaz na abordagem terapêutica inicial das ceratites infecciosas.

Descritores: Úlceras de córnea/quimioterapia; Cefalotina/uso terapêutico; Gentamicina/ uso terapêutico; Ciprofloxacino/uso terapêutico; Testes de sensibilidade microbiana: Resistência microbiana a drogas

\section{INTRODUÇÃO}

A úlcera corneana infecciosa (UCI) é um grave problema de saúde ocular, uma vez que pode resultar em grande comprometimento da visão. É uma das principais causas de cegueira monocular nos países em desenvolvimento $^{(1)}$, o que torna seu tratamento um assunto de saúde pública.

Há recomendações consistentes sobre o seu tratamento na literatura ${ }^{(2)}$. No entanto, tem-se observado marcada disparidade entre tais recomendações e a prática usual da comunidade oftalmológica ${ }^{(3)}$ em relação à realização ou não de exame microbiológico pré-tratamento e quanto à abordagem terapêutica (antibiótico) inicial.

A literatura preconiza que sejam realizados exames microbiológicos (Gram e cultura) e antibiograma, de rotina, antes da instituição do tratamento de $(\mathrm{UCI})^{(2)}$, o que levaria no manejo subseqüente, a uma eventual necessidade de troca do medicamento.

Contrariamente ao estabelecido, McDonnell et al. ${ }^{(3)}$, em revisão realizada com oftalmologistas da Califórnia, EUA, constataram que apenas cerca 
de $20 \%$ das úlceras haviam sido tratadas após coleta de material para pesquisa etiológica, o que talvez seja atribuído à prática, cada vez mais freqüente, da utilização de antibióticos de amplo espectro ${ }^{(4)}$, bem como à combinação de antibióticos fortificados, com resultados satisfatórios.

Com o objetivo de avaliar a resposta terapêutica inicial instituída para UCI correlacionando-a com os achados laboratoriais, foram estudados prospectivamente 24 casos de UCI, atendidos no Setor de Córnea e Patologia Externa do Hospital do Servidor Público Estadual em São Paulo, SP.

\section{MÉTODOS}

Realizou-se um estudo clínico, prospectivo, envolvendo pacientes com diagnóstico de UCI, atendidos no Setor de Córnea e Patologia Externa do Serviço de Oftalmologia do Hospital do Servidor Público Estadual de São Paulo, no período entre julho de 1997 e novembro de 1999.

Os pacientes foram submetidos a um protocolo constituído de história e exame oftalmológico completos, com ênfase na identificação de fatores predisponentes sistêmicos e oculares, tratamento antimicrobiano tópico prévio e gravidade da úlcera ${ }^{(5)}$. Eram consideradas úlceras graves, quando em posição central, com diâmetro igual ou maior que $4 \mathrm{~mm}$ e com mais de $2 / 3$ de profundidade; já as úlceras moderadas apresentavam posição periférica, diâmetro menor que $4 \mathrm{~mm}$ e com menos de $2 / 3$ de profundidade.

A colheita do material foi realizada pelos oftalmologistas envolvidos no protocolo, com utilização de espátula de Kimura modificada, após instilação de colírio anestésico, e raspagem do fundo e bordas da lesão, conforme descrito na literatura ${ }^{(6)}$.

Foi realizada semeadura em placas de ágar-sangue, ágarchocolate, ágar-Sabouraud, meio líquido enriquecido com tioglicolato e o exame direto realizado pelas técnicas de coloração de Gram e Giemsa.

Os exames foram efetuados pelos Departamentos de Bacteriologia (Gram e cultura) e Anatomia Patológica (Giemsa) do laboratório geral do Hospital. Foram feitas identificações dos microrganismos recuperados pelos métodos manuais recomendados pelo "Manual of Microbiology" ou por sistemas automatizados "Vitek" (Biolar-Menieux) e teste de sensibilidade pelo método de difusão de Kirby e Bauer. Os resultados de Gram estavam disponíveis em 48 horas, para bactérias e o Giemsa e cultura para fungos, em 15 dias. Culturas foram consideradas negativas após 5 dias de incubação.

Nos casos em que houve uso prévio de antibiótico tópico, suspendeu-se a medicação por um período mínimo de 48 horas.

Os pacientes foram submetidos ao tratamento com uso de colírios fortificados de cefalotina $(50 \mathrm{mg} / \mathrm{ml})$ e gentamicina $(14 \mathrm{mg} / \mathrm{ml})$, em úlceras graves, ou ciprofloxacina $0,3 \% \mathrm{em}$ úlceras moderadas, a cada hora, além de colírio ciclopentolato de 8/8 horas, com acompanhamento ambulatorial diário ou internação hospitalar nos casos mais graves. Houve troca ou retirada do antibiótico de acordo com a evolução clínica da úlcera e a sensibilidade aos antibióticos apresentada no antibiograma.

Foi considerado critério de cura do processo infeccioso: a redução da dor, resolução do infiltrado e desaparecimento da reação de câmara anterior ${ }^{(7)}$.

\section{RESULTADOS}

Vinte e quatro pacientes com UCI foram acompanhados no Serviço de Oftalmologia do Hospital do Servidor Público Estadual (HSPE). Treze $(54,16 \%)$ destes pacientes eram do sexo masculino e onze $(45,84 \%)$, do feminino; a idade variou entre 18 e 86 anos (média 59,6).

Dezessete culturas $(70,83 \%)$ foram positivas e sete $(29,17 \%)$ negativas. Das dezessete, isolou-se apenas um agente etiológico em dezesseis (94,12\%): Staphylococcus epidermidis, cinco casos (31,25\%); Pseudomonas aeruginosa, quatro casos (25\%); Staphylococcus aureus, dois casos (12,5\%); Enterobacter $s p$, dois casos (12,5\%); Streptococcus pneumoniae, dois casos (12,5\%) e Streptococcus viridans, um caso (6,25\%). Uma única cultura $(5,88 \%)$ apresentou crescimento misto de Staphylococcus epidermidis e Enterococcus. Não houve crescimento de fungos. (Tabela 1)

Apenas em três amostras com exame direto corado pelo método de Gram foi evidenciado microrganismo, sendo que em duas $(8,33 \%)$ houve correlação com a cultura. Seis casos (25\%) apresentaram bacterioscopia e culturas negativas, dos quais $4(66,67 \%)$ fizeram uso de antibiótico prévio. (Tabela 2)

Os pacientes foram tratados com antibióticos tópicos: 21 casos de úlceras graves $(87,5 \%)$, com antibióticos (gentamicina $14 \mathrm{mg} / \mathrm{ml}$ e cefalotina $50 \mathrm{mg} / \mathrm{ml}$ ) e 3 casos de úlceras moderadas $(12,5 \%)$, com ciprofloxacina.

Tabela 1. Microrganismos isolados na cultura de 24 casos de úlcera de córnea no serviço de oftalmologia do HSPE
Microrganismo

Staphylococcus epidermidis

Pseudomonas aeruginosa

Staphylococcus aureus

Streptococcus pneumoniae

Streptococcus viridans

Enterococcus

Total
Enterobacter sp
$6(33,33 \%)$

$4(22,22 \%)$

$2(11,11 \%)$

$2(11,11 \%)$

$1 \quad(5,56 \%)$

$1 \quad(5,56 \%)$
Número (\%)

$2(11,11 \%)$

\begin{tabular}{|c|c|c|c|c|}
\hline & & \multicolumn{2}{|c|}{ Cultura } & \multirow[t]{2}{*}{ Total } \\
\hline & & + & - & \\
\hline Gram & + & 02 & 01 & 03 \\
\hline Gram & - & 15 & 06 & 21 \\
\hline Total & & 17 & 07 & 24 \\
\hline
\end{tabular}


Três pacientes (12,5\%) apresentaram piora clínica, mesmo após a introdução dos colírios iniciais. Em dois deles, houve identificação do agente (Streptococcus viridans e Staphylococcus epidermidis). Com base no antibiograma, verificou-se a resistência aos colírios fortificados introduzidos inicialmente, modificando-se a medicação tópica por vancomicina $25 \mathrm{mg} / \mathrm{ml}$. Em um destes casos com cultura negativa, também foi feita a troca dos colírios fortes por vancomicina $25 \mathrm{mg} / \mathrm{ml}$ e amicacina $25 \mathrm{mg} / \mathrm{ml}$. Os três casos evoluíram com resolução do quadro após a modificação da medicação. Os 21 pacientes restantes $(87,5 \%)$ não necessitaram de troca da medicação inicial.

Todos os pacientes (100\%) cursaram com a cura do processo infeccioso segundo critério utilizado. Dezessete $(70,83 \%)$ mantiveram a acuidade visual pré-tratamento ou apresentaram melhora. Três (12,5\%) apresentaram acuidade visual reduzida após a resolução do processo infeccioso, devido à opacidade de córnea. Dois pacientes $(8,33 \%)$, previamente amauróticos, tiveram o processo infeccioso controlado, porém evoluíram com afinamento da córnea e perfuração e, por apresentarem olho doloroso, foram eviscerados.

Em alguns pacientes, tornou-se necessário utilização de tratamento concomitante para resolução do processo de afinamento da córnea secundários a alterações de superfície. Quatro pacientes $(16,67 \%)$ apresentaram defeito epitelial persistente, sendo que três deles foram submetidos à tarsorrafia com resolução do quadro, e um, a recobrimento conjuntival,. Um paciente $(4,17 \%)$, com percepção luminosa, evoluiu com afinamento, sendo submetido a transplante tectônico. Um paciente $(4,17 \%)$, com herpes como fator predisponente, evoluiu com perfuração ocular, sendo submetido à aplicação de adesivo tecidual e colocação de lente de contato terapêutica e encontra-se aguardando transplante de córnea. (Tabela 3 )

\section{DISCUSSÃO}

A introdução de antibióticos de amplo espectro de ação no tratamento da úlcera de córnea infecciosa vem tornando cada vez mais freqüente a discussão sobre a real necessidade de realização de Gram e cultura pré-tratamento ${ }^{(3)}$.

No presente estudo, em apenas 3 casos $(12,5 \%)$ houve identificação do tipo de organismo por meio da bacterioscopia (Gram), resultado inferior ao descrito por Lima et al. ${ }^{(8)}$ que descreveu positividade de $41 \%$ em 1988 e de $50,2 \%$ em estu$\mathrm{do}^{(9)}$ do mesmo grupo realizado doze anos após. Existe na literatura uma grande variação sobre a sensibilidade deste exame. Em 1997, Levey e col ${ }^{(10)}$ descreveram positividade do gram de $0 \%$. Justificaram que estes resultados poderiam ser decorrentes ao processamento de tais exames em laboratório geral do hospital, acreditando que os técnicos não estivessem adequadamente treinados para detecção de pequena quantidade de organismos nas espécimes oculares comparadas as espécimes não oculares.

Em apenas 2 casos $(8,33 \%)$ foi observada correlação entre os achados de Gram e cultura. Resultados também inferiores

\begin{tabular}{|c|c|c|}
\hline Pac. & $\mathbf{A V i}$ & Avf \\
\hline 1 & MM & ${ }^{*} \mathrm{PL}$ \\
\hline 2 & $20 / 60$ & $20 / 25$ \\
\hline 3 & CD $10 \mathrm{~cm}$ & $20 / 30$ \\
\hline 4 & MM & ${ }^{*} \mathrm{MM}$ \\
\hline 5 & MM & CD $4 \mathrm{~m}$ \\
\hline 6 & $20 / 80$ & $20 / 40$ \\
\hline 7 & PL & ${ }^{*} \mathrm{CD} 10 \mathrm{~cm}$ \\
\hline 8 & $\mathrm{MM}$ & ${ }^{* *} \mathrm{PL}$ \\
\hline 9 & $20 / 20$ & $20 / 20$ \\
\hline 10 & $\mathrm{MM}$ & MM \\
\hline 11 & $20 / 20$ & $20 / 40$ \\
\hline 12 & SPL & ${ }^{* * *}$ SPL \\
\hline 13 & $20 / 25$ & $20 / 25$ \\
\hline 14 & $20 / 100$ & $20 / 100$ \\
\hline 15 & PL & PL \\
\hline 16 & SPL & SPL \\
\hline 17 & $20 / 20$ & $20 / 20$ \\
\hline 18 & $\mathrm{PL}$ & $\mathrm{MM}$ \\
\hline 19 & SPL & ${ }^{* * *} \mathrm{SPL}$ \\
\hline 20 & $\mathrm{MM}$ & MM \\
\hline 21 & $20 / 40$ & $20 / 40$ \\
\hline 22 & $\mathrm{PL}$ & CD 1m \\
\hline 23 & SPL & SPL \\
\hline 24 & SPL & SPL \\
\hline \multicolumn{3}{|c|}{$\begin{array}{l}\text { AVi - acuidade visual no diagnóstico; } A V f \text { - acuidade visual final; } \mathrm{SPL} \text { - sem } \\
\text { percepção luminosa; } \mathrm{PL} \text { - percepção luminosa; } \mathrm{MM} \text { - movimento de mãos; } \mathrm{CD} \\
\text { - conta dedos; }{ }^{*} \text { submetido à tarsorrafia; }{ }^{* *} \text { submetido ao recobrimento } \\
\text { conjuntival; }{ }^{* * *} \text { submetido à evisceração }\end{array}$} \\
\hline
\end{tabular}

aos encontrados por McLeod e col. ${ }^{(11)}$, na literatura internacional, e por Paro e col. ${ }^{(12)}$, na literatura brasileira, que encontraram correspondência em $26,8 \%$ e $36,0 \%$ dos casos de úlceras, respectivamente.

Em 17 úlceras (70,83\%), foi observado crescimento bacteriano na cultura, sendo que em 16 houve identificação de apenas um organismo e, em 1 caso, duas bactérias foram isoladas. Dos organismos identificados na cultura, os mais encontrados foram Staphylococcus epidermidis, Pseudomonas aeruginosa e Staphylococcus aureus, resultados compatíveis com os descritos na literatura em estudos de Lima, McLeod, Paro, Rodman e Sampaio ${ }^{(8-14)}$.

Todos os pacientes foram tratados inicialmente com associação de antibióticos fortificados (gentamicina e cefalotina 21 casos) ou antibióticos de amplo espectro (ciprofloxacina $0,3 \%-3$ casos). Em apenas 3 casos (12,5\%), houve necessidade de substituição do tratamento inicial, já que apresentaram piora clínica. A modificação do tratamento foi feita de acordo com resultados da cultura e antibiograma em dois destes pacientes.

McLeod e col. ${ }^{(11)}$ evidenciaram, em seu estudo, que a maioria das UCI adquiridas na comunidade apresentou resposta satisfatória ao tratamento empírico de longo espectro, havendo a necessidade de mudança em apenas $4 \%$ dos casos (úlceras graves), depois de serem efetuados testes microbiológicos. 
Mutton e col..$^{(5)}$ estudando 48 úlceras presumivelmente bacterianas, detectaram a necessidade de mudança em $10 \mathrm{ca}-$ sos $(20,8 \%)$, sendo que 7 foram orientadas pelo laboratório.

Rodman e col. ${ }^{(13)}$ encontraram resultados semelhantes, apresentando $10 \%$ de necessidade de troca da medicação inicial em serviço de córnea de referência, contrastando com clínica geral, onde nenhum paciente necessitou de troca da medicação. Justificaram para tais achados: a menor severidade da úlcera, curta duração dos sintomas e poucos fatores de risco predisponentes. Levey e col. ${ }^{(10)}$ também descreveram necessidade de troca da medicação em $6,7 \%$ dos casos.

Neste estudo, evidenciou-se que a utilização de antibióticos de amplo espectro ou colírios fortificados como terapêutica inicial das ceratites infecciosas foi eficaz em vinte e um pacientes $(87,5 \%)$.

Embora os testes microbiológicos requeiram custos adicionais e laboratórios especializados, não sendo utilizados pela comunidade em úlceras de córnea infecciosas leves à moderadas, são de fundamental importância para as úlceras graves ou sem resposta inicial favorável ao tratamento, principalmente pelas seqüelas anatômicas resultantes do processo infeccioso que pode levar a grande comprometimento da visão ${ }^{(15)}$.

\section{CONCLUSÃO}

Serviços de referência terciária e centros de tratamento de especialistas devem manter a recomendação de colheita de material da úlcera para cultura rotineiramente, pois são estes serviços a referência para os casos mais severos. Além disso, são responsáveis pela documentação da variação da sensibilidade antibiótica, bem como das alterações nos agentes mais prevalentes naquela determinada região e no decorrer dos anos, disseminando conhecimentos e orientações para a comunidade oftalmológica.

\section{ABSTRACT}

Purpose: To evaluate the initial treatment of infectious corneal ulcers and their laboratory tests. Methods: Twenty four cases of infectious corneal ulcers seen in the External Corneal Disease Section at the Hospital do Servidor Público Estadual - São Paulo - Brazil, underwent Gram staining and culture for bacterial and fungus. Treatment with fortified cefalotine $(50 \mathrm{mg} / \mathrm{ml})$ and gentamicin $(14 \mathrm{mg} / \mathrm{ml})$ was started. Results: Seventeen cultures $(70.83 \%)$ were positive for bacterial infection and seven $(29.17 \%)$ showed no growth. In three cases $(15.76 \%)$ the Gram staining showed correlation with the culture. Three cases did not respond to the initial treatment and had the medications changed according to the results of the cultures. All patients responded to the clinical treatment. Conclusions: Ours results showed that combination of fortified cefalotine and gentamicin eye drops was efficient to treat most of the infectious corneal ulcers.

Keywords: Corneal ulcers/drug therapy; Cephalothin/therapeutic use; Gentamicins/therapeutic use; Ciprofloxacin/therapeutic use; Microbial sensitivity tests; Microbial drug resistance

\section{REFERÊNCIAS}

1. Srinivasan M, Gonzales CA, George C, Cevallos V, Mascarenhas JM, Asokan B, et al. Epidemiology and aetiological diagnosis of corneal ulceration in Madurai, South India. Br J Ophthalmol 1997;81:965-71.

2. Jones DB. Decision-making in the management of microbial keratitis. Ophthalmology 1981;88:814-20.

3. Meyers SJ, Varley GA, Meisler DM, Camisa C, Wander AH. Community care of corneal ulcers [commented on Am J Ophthalmol 1992;114:630-2]. Am J Ophthalmol 1992;114:531-8.

4. Parks DJ, Abrams DA, Sarfarazi FA, Katz HR. Comparison of topical ciprofloxacin to conventional antibiotic in the therapy in the treatment of ulcerative keratitis. Am J Ophthalmol 1993;115:471-7.

5. Mutton FL, Kakinowana E, Alves MR, Arieta CEL, Kara José N. Considerações sobre o tratamento de úlceras corneanas presumivelmente bacterianas. Arq Bras Oftalmol 1997;60:258-61.

6. Tomimatsu PI, Belfort Jr. R, Kara José N. Microbiologia e citologia da córnea. In: Belfort Júnior R, Kara Jose N. Córnea clínica e cirúrgica. São Paulo: Roca;1997. p.65-95.

7. O'Brien TP. Bacterial keratites. In: Krachmer M, Holland P. Córnea. St. Louis: Mosby 1996. cap 94.

8. Lima ALH, Nishi M, Lottemberg CL, Guidugli T. Úlcera de córnea em serviço de referência. Arq Bras Oftalmol 1988;51:118-20.

9. Wakisaka E, Ferreira MA, Rocha FJ, Freitas LL, Guidugli T, Lima ALH. Cultura de material provindo de úlceras de córnea em laboratório de referência. Arq Bras Oftalmol 1990;53:196-200.

10. Levey SB, Katz HR, Abrams DA, Hirschbein MJ, Marsh MJ. The role of cultures in the Management of ulcerative keratitis [commented on Cornea 1997;16:381-2]. Cornea 1997;16:383-6.

11. McLeod SD, Kolahdouz-Isfahoni A, Rostamian K, Flowers CW, Lee PP, McDonnell PJ. The role of smears, cultures, and antibiotic sensitivity testing in the management of suspected infectious keratitis [commented on Ophthalmology 1996;103:1165-6). Ophthalmology 1996;103:23-8.

12. Paro G, Zanardo S, Chicani CF, Gomes JAP, Lima Filho AAS, Cunha MC. Correlação entre bacterioscopia e cultura nas úlceras de córnea e as implicações do uso de antibiótico prévio. Rev Bras Oftalmol 1998;57:823-7.

13. Rodman RC, Spisak S, Sugar A, Meyer RF, Soong, HK, Musch DC. The utility of culturing corneal ulcers in a tertiary referral center versus a general ophthalmology clinic. Ophthalmology 1997;104:1897-901.

14. Sampaio CM, Alves MR, Kara José N, Sciamarella CF. Avaliação clínica do tratamento tópico das úlceras de córnea bacterianas com ciprofloxacina à $0,3 \%$. Arq Bras Oftalmol 1994:57:329-32.

15. McLeod SD, LaBree LD, Tayyanipour R, Flowers CW, Lee PP, McDonnell PJ. The importance of initial management in treatment of severe infectious corneal ulcers. Ophthalmology 1995;102:1943-8. 